\title{
Production of Biodiesel from Waste Cooking Oil: A Review
}

\author{
A. Geetha Bhavani ${ }^{1, *}$, Varun Kumar Sharma ${ }^{2}$ \\ ${ }^{1}$ Department of Chemistry, NIU Research and Innovation Centre, Noida International University, Greater Noida - 201308, UP, India. \\ ${ }^{2}$ Department of Biotech. and Microbiology, School of Science, NIU Research and Innovation Centre, Noida Int. University, Greater Noida - 201308, UP, India.
}

\section{ART ICLE DETAILS}

Article history:

Received 02 April 2018

Accepted 13 April 2018

Available online 26 April 2018

\section{Keywords:}

Biodiesel

Waste Vegetable Oils

Transesterification

\section{A B S T R A C T}

Biodiesel is a liquid transportation fuel that can be produced from renewable raw material such as waste cooking oil. The use of cooking oil as raw material for biodiesel production will enhance the viability of the food industry. Biodiesel, and the process is called transesterification. It is a chemical process in which a triglyceride in the vegetable oils and fat reacts with alcohol in the presence of a strong acid or base to produce a mixture of fatty acids alkyl esters (FAAE) and glycerol. Technologies of transesterification of vegetable oils into fatty acid methyl esters (FAME) called biodiesel, have been experimentally established and are well documented in the open literature. But, no previous work using ultrasonic tubular reactor in biodiesel process was explored. This study will provide useful data for society in the biodiesel process.

\section{Introduction}

Biodiesel is an alternative diesel fuel derived from vegetable oils or animal fats. The main components of vegetable oils and animal fats are triglycerides or also known as ester of fatty acid attached to glycerol. One of the main driving force for biodiesel widespread is the greenhouse gas emission ( $\mathrm{CO}_{2}$ being the major one). The term waste cooking oil (WCO) refers to vegetable oil has been in food production and which is no longer viable for its intended use [1]. WCO arises from many different sources, including domestic, commercial and industrial. WCO is a potentially problematic waste stream which requires proper management. The disposal of WCO can be problematic when disposed incorrectly. Any fatty acid sources may be used to produce biodiesel. Therefore, any animal or plant lipid should be ready substrate for the production of biodiesel [2]. The use of edible vegetable oils and animal fats for biodiesel production has recently been of great concern because they compete with food material and the food versus fuel dispute.

Biodiesel can be produced from any material that contains fatty acids, be they linked to other molecules or present as free fatty acids. Thus various vegetable fats and oils, animal fats, waste greases, and edible oil processing wastes can be used as feed stocks for biodiesel production. The choice of feedstock is based on such variables as local availability, cost, government support and performance as a fuel [3]. The primary feedstock is a vegetable oil or animal fat, biodiesel is generally considered to be renewable. Since the carbon in the oil or fat originated mostly from carbon dioxide in the air, biodiesel is considered to contribute much less to global warming than fossil fuels. Diesel engines operated on biodiesel have lower emissions of carbon monoxide, unburned hydrocarbons, particulate matter, and air toxics than when operated on petroleum-based diesel fuel [4].

Most cooking oil are made from palm oil. In the fast food business alone, a single branch which serves fried food such as fried chicken, French fries and burgers can produce as much as 15 liters of cooking oil per day. About $40 \%$ of palm oil mostly made into cooking oil, margarine, specialty fats and oleochemicals. Considering that hundreds of these outlets generated can reach several thousand liters per day. Several properties of degraded used cooking oil after it gets into sewage. Nowadays the humanity is facing new important challenges; lifestyles and human activities are based in materialism and consume of highly processed goods that are also dependent on energy consumption at a high level. Therefore each year the amount of wastes are increasing and the traditional sources of energy, mainly fossil fuels are reducing.

There are several factors that point to cause the high levels on waste generation; the increase in world population, high levels of consumption, the increasing wealth of countries and the high technological development. The focus of many biodiesel producers is currently to get production facilities up and running as quickly as possible to take advantage of current demand, both consumer and political driven. As the process is fairly well known, well developed, and relatively simple to design, build and operate, rigorous simulation is only now generating strong interest. This has illuminated significant value-add opportunity in the optimization of the processes, including energy usage and reactor conversion, for the many forward-looking biodiesel producers and process development groups.

The overview of the four important issues in biodiesel production has been briefly explained. These four issues i.e., economic analysis of current and future sources of energy, selection of a reliable feedstock as a raw material, selection of a suitable process depending on the source of the feedstock and selection of a suitable catalyst to improve the performance of biodiesel synthesis.

The main focus of this research work is to create a green and environmentally benign process for biodiesel production by using an effective catalyst and to reduce the dependency on food supplement materials i.e. vegetable oils as the feedstocks. Some of the advantages of using biodiesel as a replacement for diesel fuel are, (i) renewable fuel, obtained from vegetable oils or animal fats, (ii) low toxicity, in comparison with diesel fuel, (iii) degrades more rapidly than diesel fuel, minimizing the environmental consequences of biofuel spills, (iv) lower emissions of contaminants: carbon monoxide, particulate matter, polycyclic aromatic hydrocarbons, aldehydes, (v) lower health risk, due to reduced emissions of carcinogenic substances, (vi) no sulfur dioxide $\left(\mathrm{SO}_{2}\right)$ emissions, (vii) higher flash point $\left(100^{\circ} \mathrm{C}\right.$ minimum), (viii) may be blended with diesel fuel at any proportion; both fuels may be mixed during the fuel supply to vehicles, (viiii) excellent properties as a lubricant, (ix) it is the only alternative fuel that can be used in a conventional diesel engine, without modifications, (x) used cooking oils and fat residues from meat processing may be used as raw materials [5].

Biodiesel is an excellent alternative fuel for diesel engines. It is made from agricultural products. It is most commonly made from oil extracted from soyabeans, one of the top agricultural products. There is a lot of interest in biodiesel production across the world. In general, biodiesel can be produced from any of the following: pure vegetable oil (soybean, canola, sunflowers); rendered animal fats; or waste cooking oil. The oil is converted to biodiesel through a chemical process called transesterification. Glycerin is removed as a by-product of the reaction, 
and the resulting fuel can be blended with petroleum diesel, or used directly as a neat fuel. Biodiesel should be evaluated according to the protocols outlined in the Biodiesel Standard ASTM-D6751 (American Society for Testing and Materials) before use. This new research presents the procedures for producing biodiesel, with particular emphasis on small-scale production.

\section{Chemical Components Involved in Biodiesel Production}

The raw materials for biodiesel production are vegetable oils, animal fats and short chain alcohols. The oils most used for worldwide biodiesel production are rapeseed (mainly in the European Union countries), soybean (Argentina and the United States of America), palm (Asian and Central American countries) and sunflower, although other oils are also used, including peanut, linseed, safflower, used vegetable oils, and also animal fats. Methanol is the most frequently used alcohol although ethanol can also be used. Since cost is the main concern in biodiesel production and trading (mainly due to oil prices), the use of non-edible vegetable oils has been studied for several years with good results. Besides its lower cost, another undeniable advantage of non-edible oils for biodiesel production lies in the fact that no foodstuffs are spent to produce fuel [1]. These and other reasons have led to medium- and large-scale biodiesel production trials in several countries, using non-edible oils such as castor oil, tung, cotton, jojoba and jatropha. Animal fats are also an interesting option, especially in countries with plenty of livestock resources, although it is necessary to carry out preliminary treatment since they are solid; furthermore, highly acidic grease from cattle, pork, poultry, and fish can be used. Microalgae appear to be a very important alternative for future biodiesel production due to their very high oil yield; however, it must be taken into account that only some species are useful for biofuel production. Although the properties of oils and fats used as raw materials may differ, the properties of biodiesel must be the same, complying with the requirements set by international standards.

Any vegetable oil or animal fat can be used as a feedstock for biodiesel production; as these are natural products, they are mixtures of several component oils and fats. These oils/fats are triglyceride molecules (glycerin esterified with three fatty acids). The -Rx groups shown here varies according to the source of the oil/fat: Biodiesel is produced by the chemical modification of animal or vegetable fat or oil to obtain a product with diesel-like properties. This is obtained through the technology seen in Fig. 1 thus creating a reaction between oils or fats and methanol to create fatty acid methyl ester (FAME) or biodiesel.

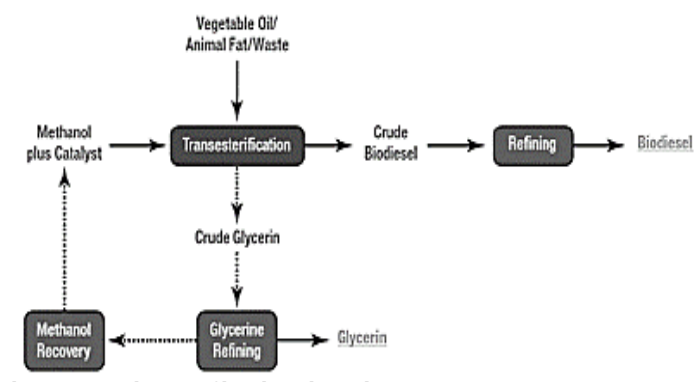

Fig. 1 Schematic pathway of biodiesel production

This process is called transesterification and only creates glycerine as a bi-product. Roughly speaking, 100pounds of oil or fat are reacted with 10 pounds of a short-chain alcohol (usually methanol) in the presence of a catalyst (usually sodium hydroxide or rarely potassium hydroxide to form 100 pounds of biodiesel and 10pounds of glycerine. Glycerine is used in pharmaceuticals and cosmetics among other markets. All types of vegetable, animal oils and fats can be used for biodiesel production, as all oils and fats have the same fundamental structure. Only the content of specific fatty acids is different, including the content of unsaturated fatty acids relative to saturated. Among other differences, the most important is that a high content of saturated fatty acids increases the solidification point, while a high content of unsaturated fats lowers it. For instance, because of their different composition, biodiesel from animal fats solidifies at a higher temperature than biodiesel made from vegetable oils due to a higher level of saturated fatty acids. This is especially relevant when operating an engine with biodiesel, because it is used in a wide spectrum of temperatures.

\section{Transesterification Reaction for Biodiesel Production}

Biodiesel is made through transesterification between triglyceride and alcohol (usually in the form of methanol). As shown in Fig. 2, the https://doi.org/10.30799/jacs.181.18040105 triglyceride molecule is like a capital letter " $E$ ", where the three "arms' of the capital "E" represent three long-chain fatty acids. In transesterification, methanol molecules replace the "backbone" and link the "arms" of the capital "E" to form three linear molecules (Fig. 3). This new linear molecule is called a "methyl-ester", which is the scientific term for biodiesel.

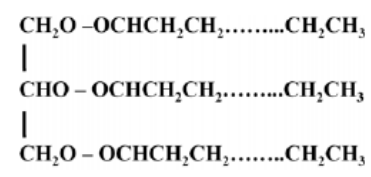

Fig. 2 Molecular structure of triglycerides

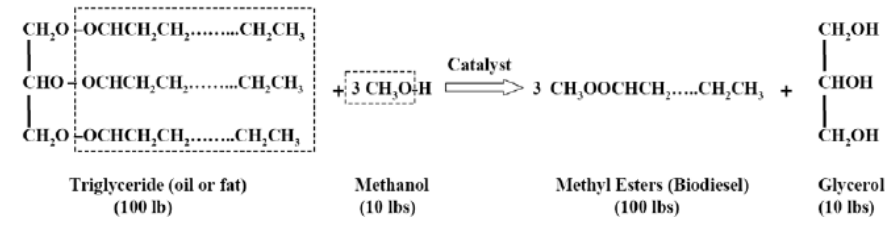

Fig. 3 Chemical reaction for biodiesel production transesterification

The theoretical ratio of methanol to triglyceride is $3: 1$; which corresponds to having one methanol molecule for each of the three hydrocarbon chains present in the triglyceride molecule, and is equivalent to approximately $12 \%$ methanol by volume. In practice, this ratio needs to be higher in order to drive the reaction towards a maximum biodiesel yield; $25 \%$ by volume is recommended. The catalyst can be alkalis, acids, or enzymes (e.g., lipase) [6]. The majority of biodiesel produced today is done with the alkalis-catalyzed reaction because this reaction (1) requires only low temperature and pressure, (2) has a high conversion yield (98\%) with minimal side reaction and a short reaction time, (3) is a direct conversion to biodiesel with no intermediate compounds, and (4) does not need elaborate construction materials. Biodiesel is a liquid biofuel obtained by chemical processes from vegetable oils or animal fats and an alcohol that can be used in diesel engines, alone or blended with diesel oil. ASTM defines biodiesel as a mixture of long-chain monoalkylic esters from fatty acids obtained from renewable resources, to be used in diesel engines.

Blends with diesel fuel are indicated as " $\mathrm{Bx}$ ", where " $\mathrm{x}$ " is the percentage of biodiesel in the blend. For instance, "B5" indicates a blend with $5 \%$ biodiesel and $95 \%$ diesel fuel; in consequence, B100 indicates pure biodiesel.

\subsection{Characteristics of Oils and Fats Used in Biodiesel Production}

Oils and fats, known as lipids, are hydrophobic substances insoluble in water and are of animal or vegetal origin. They differ in their physical states at room temperature. From a chemical viewpoint, lipids are fatty glycerol esters known as triglycerides [8]. The general chemical formula is shown in Fig. 4, $R_{1}, R_{2}$ and $R_{3}$ represent hydrocarbon chains of fatty acids, which in most cases vary in length from 12 to 18 carbon atoms, respectively. The three hydrocarbon chains may be of equal or different lengths, depending on the type of oil; they may also differ on the number of double-covalent bonds in each chain.

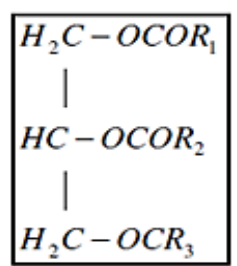

Fig. 4 General chemical formula of triglycerides

Fatty acids may be saturated fatty acids (SFA) or non-saturated fatty acids (NSFA). In the former, there are only single covalent bonds in the molecules. The names of the most important fatty acids in oils are listed in Table 1 along with their chemical formulas The notation x:y indicates the number of carbon atoms in the oil molecule $(x)$ and the number of unsaturations, i.e. double-covalent bonds (y). For instance, $y=0$ for all the SFAs. The most frequent fatty acids in oils are lauric, palmitic, estearic, linoleic and linolenic, although others may also be present. It is important to note that vegetable oils differ in their content of fatty acids. For instance, ricinoleic acid is the main component of castor oil, whereas in olive oil it is oleic acid, in soybean oil it is linoleic acid, and in linseed oil it is linolenic acid [9]. 
Table 1 Chemical formula of the main fatty acid in vegetables oil

\begin{tabular}{ll}
\hline Fatty Acid & Chemical Formula \\
\hline Lauric (12:0) & $\mathrm{CH}_{3}\left(\mathrm{CH}_{2}\right)_{10} \mathrm{COOH}$ \\
Palmitic (16:0) & $\mathrm{CH}_{3}\left(\mathrm{CH}_{2}\right)_{14} \mathrm{COOH}$ \\
Estearic (12:0) & $\mathrm{CH}_{3}\left(\mathrm{CH}_{2}\right)_{16} \mathrm{COOH}$ \\
Oleic (18:1) & $\mathrm{CH}_{3}\left(\mathrm{CH}_{2}\right)_{7} \mathrm{CH}=\mathrm{CH}\left(\mathrm{CH}_{2}\right)_{7} \mathrm{COOH}$ \\
Linoleic (18:3) & $\mathrm{CH}_{3}\left(\mathrm{CH}_{2}\right)_{4} \mathrm{CH}=\mathrm{CHC} \mathrm{H} \mathrm{CH}_{2} \mathrm{CH}\left(\mathrm{CH}_{2}\right)_{7} \mathrm{COOH}$ \\
Erucic $(22: 1)$ & $\mathrm{CH}_{3} \mathrm{CH}_{2}(\mathrm{CH}=\mathrm{CH} \mathrm{CH})_{3}\left(\mathrm{CH}_{2}\right)_{5} \mathrm{COOH}$ \\
Ricinoleic (18:1) & $\mathrm{CH}_{3}\left(\mathrm{CH}_{2}\right)_{7} \mathrm{CH}=\mathrm{CH}\left(\mathrm{CH}_{2}\right)_{11} \mathrm{COOH}$ \\
\hline
\end{tabular}

Vegetable oils may also contain small percentages of monoglycerides and diglycerides. In addition, there will also be small amounts of free fatty acids (in most vegetable oils, less than $1 \%$, except for palm oil, where they can reach up to 15\%). The composition of vegetable oils influences their properties (The European Parliament and the Council's Directive of $2009 / 28 / E F$ ). For instance, the pour point and cloud point temperatures, cetane number and the iodine index depend on the number of unsaturations and the length of the fatty acid chains. A higher content of double-covalent bonds gives a lower solidification point and a higher iodine index.

\subsection{Characteristics of Alcohols Used in Biodiesel Production}

Alcohols that can be used in biodiesel production are those with short chains, including methanol, ethanol, butanol, and amylic alcohol. The most widely used alcohols are methanol $\left(\mathrm{CH}_{2} \mathrm{OH}\right)$ and ethanol $\left(\mathrm{C}_{2} \mathrm{H}_{5} \mathrm{OH}\right)$ because of their low cost and properties. Methanol is often preferred to ethanol in spite of its high toxicity because its use in biodiesel production requires simpler technology; excess alcohol may be recovered at a low cost and higher reaction speeds are reached [10]. It must be remembered that in order for biodiesel to be a fully renewable fuel, it should be obtained from vegetable oils and animal fats, together with an alcohol that is produced from biomass, such as bioethanol, instead of being a petrochemical product.

\section{Various Catalysts used in Biodiesel Production}

A catalyst is the key to chemical transformation. According to the catalyst for biodiesel production falls into three categories, namely the homogeneous catalyst, the heterogeneous catalyst and the enzyme catalyst.

\subsection{Homogeneous Catalyst}

Homogeneous catalysis is a chemical term which describes a catalysis reaction where the catalyst is in the same phase as the reactant. The homogeneous catalyst for biodiesel process is divided into two categories, which are the acid and the base catalysts.

\subsection{Homogeneous Acid Catalyst}

The most common acid catalysts being used in biodiesel production are sulphuric acid, phosphoric acid, hydrochloric acid or organic sulfonic acid. The most popular acid catalyst is sulphuric acid. One percent (v/v) of $100 \% \mathrm{H}_{2} \mathrm{SO}_{4}$ or $\mathrm{HCl}$ is commonly the preferable amount of catalyst selected by most of the researchers [11].

\subsection{Homogeneous Base Catalyst}

According to Barthomeuf et al. [9], the most effective base catalysts are potassium hydroxide, potassium methoxide, sodium hydroxide and sodium methoxide. There are many contradictory findings between these homogeneous base catalysts. Sodium methoxide $\left(\mathrm{CH}_{3} \mathrm{ONa}\right)$ and potassium methoxide $\left(\mathrm{CH}_{3} \mathrm{OK}\right)$ were claimed to perform better compared to sodium hydroxide $(\mathrm{NaOH})$ and potassium hydroxide $(\mathrm{KOH})$ [19]. They found that the methoxide salts have higher reaction activities compared to the hydroxides since there is negligible formation of the by-product water during the reaction. Nevertheless, these methoxide salts were relatively more expensive than the hydroxides and required high quality oils and water-free methanol. Ali and Merchant [20] also revealed similar results when $1 \%(\mathrm{w} / \mathrm{w})$ of sodium methoxide was found to be the optimum catalyst concentration to produce biodiesel from safflower oil. However, a contradictory finding was reported by Encinar et al. [21] when they investigated the transesterification of used frying oil using sodium hydroxide, potassium hydroxide, sodium methoxide and potassium methoxide as catalysts. They found that potassium hydroxide gives the highest yield when ethanol was employed as a solvent. This is due to the formation of potassium ethoxide which is a stronger base than potassium methoxide. A similar comparison study between potassium hydroxide and sodium hydroxide and potassium hydroxide was found to have a higher yield $(91.67 \%)$ as compared to sodium hydroxide $(85.9 \%)$ but the purity of FAME obtained was similar. However, results from potassium hydroxide was less effective than the sodium based catalyst in terms of its purity. However, research focus on the use of sodium hydroxide $\left(\mathrm{H}_{2} \mathrm{SO}_{4}\right)$ and potassium hydroxide $(\mathrm{KOH})$ as a base catalyst.

\subsection{Heterogeneous Catalyst}

Heterogeneous catalysis is a chemical term which describes a catalysis reaction where the catalyst is in a different phase to the reactants. Similar to homogeneous catalysts, the heterogeneous catalyst is also divided into two categories, i.e. the solid base and the solid acid catalyst. The popularity of heterogeneous catalysts nowadays is due to the limitations caused by homogeneous catalysts. The conventional homogeneous catalyst is recommended to be replaced by environmentally friendly heterogeneous catalyst as this type of catalyst is proven to simplify the production and purification processes, reduced the amount of wastewater and cut off the number of process equipment. Therefore, the mentioned benefits will lead to a reduction in the biodiesel production cost. These catalysts were also easily separated from the reaction mixture, thus allowing multiple usage of the catalyst through a regeneration process and simultaneously this creates an environmentally friendly condition. The main obstacle faced by many researchers is the development of a suitable heterogeneous catalyst so that the transesterification process can be carried out under mild reaction conditions, within a short period of time and obtain the highest percentage of biodiesel conversion [12].

\subsection{Heterogeneous Acid Catalyst}

The heterogeneous acid catalyst became one of the most potential solid catalysts for esterification and transesterification reactions. An ideal solid acid catalyst should have high stability, numerous strong acid sites, large pores, a hydrophobic surface and a low cost. By having a suitable solid acid catalyst, it can be easily integrated into a continuous flow system, simplify the product separation and purification as well as reduce waste generation [13].

\subsection{Heterogeneous Base Catalyst}

Detailed investigation of different types of base heterogeneous catalysts such as rare earth oxides, various base metal compounds supported on alumina or zeolite, hydroxides, alkoxides, hydrotalcites and ion exchange resin have been carried out by several researchers. Solid base catalysts are reported to have high catalytic activities but low stability. Heterogeneous base catalysts are classified into 6 different categories: single metal oxide, mixed metal oxide, supported alkali/alkaline earth metal, zeolites, hydrotalcites and ion exchange resins.

\subsection{Alcohol-Catalyst Mixing}

The alcohol used for biodiesel production must be mixed with the catalyst before adding the oil. The mixture is stirred until the catalyst is completely dissolved in the alcohol. It must be noted that the alcohol must be water-free (anhydrous). Sodium and potassium hydroxides are among the most widely used basic catalysts. For production on an industrial scale, sodium or potassium methoxides or methylates are commercially available. Of course, due caution must be exercised, and all applicable safety regulations must be followed, when working with methanol, hydroxides and methoxides, independently of the production scale. The alcohol-to-oil volume ratio, $\mathrm{R}$, is another key variable of the transesterification process. The stoichiometric ratio requires $1 \mathrm{~mol}$ of oil to react with $3 \mathrm{~mol}$ of alcohol, to obtain $3 \mathrm{~mol}$ of fatty acids methyl esters (FAME) and $1 \mathrm{~mol}$ of glycerin. However, since the reaction is reversible, excess alcohol as a reactant will shift the equilibrium to the right side of the equation, increasing the amount of products (as it may be inferred from Le Chatelier's principle). Although a high alcohol-to-oil ratio does not alter the properties of FAME, it will make the separation of biodiesel from glycerin more difficult, since it will increase the solubility of the former in the latter. Usually, a $100 \%$ alcohol excess is used in practice, that is, $6 \mathrm{~mol}$ of alcohol per mole of oil. This corresponds to a 1:4 alcohol-to-oil volume ratio $(R=0.25)$. Finally, it must be noted that the necessary amount of catalyst is determined taking into account the acidity of the oil, by titration.

\subsection{Base Catalysed Transesterification}

Base catalysed transesterification is the most adoptable technology for biodiesel production. The researchers found that base transesterification can achieve a high purity and yield of biodiesel product in a short time, approximately 30-60min [17]. The base catalysed process is reported to be 4000 times faster than using the acid catalysed process. However, it is 
very sensitive to the quality of the feedstock, requiring vegetable oil, animal fats or other sources of raw material with a very low amount of FFA and water content. The reaction mechanism for the base catalysed transesterification process [18], formulated in three sequential steps, is shown in Fig. 5.

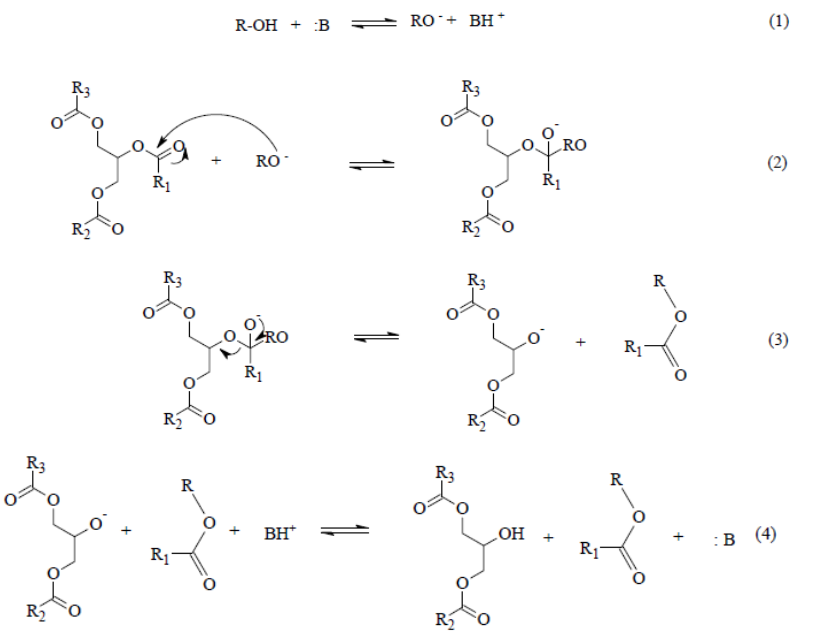

Fig. 5 The mechanism of base catalysed transesterification of triglycerides with alcohol

(1) Production of active species, RO-, (2) nucleophilic attack, (3) intermediate breakdown, (4) regeneration of active species. $R_{1}, R_{2}$ and $R_{3}$ refers to carbon chain of the fatty acid whereas $R$ refers to alkyl group of the alcohol. The first step is the reaction between the base catalyst with the alcohol, forming the alkaloid and the protonated catalyst. The carboxyl group of the triglycerides has a slight positive charge whereas the carbonyl oxygen of the alcohol has a slight negative charge. In the second step, nucleophilic attack takes place when the $\mathrm{C}=0$ bond of the triglycerides molecules is attacked by the anion of the alcohol, RO-forming the tetrahedral intermediate. This intermediate has a slight negative charge which eventually falls back to the carbon bond, forming FAAE and the anion of diglycerides. The regeneration of active species takes places by the deprotonation of the catalyst using the latter species (anion of diglycerides). Diglycerides and monoglycerides were converted by the same mechanism as triglycerides. At the end of the process, three moles of FAAE and one mole of glycerine were formed. The main difference between the acid catalysed transesterification and the base catalysed transesterification is their proton donation. Acid catalyses the reaction by donating a proton to the carboxyl group, thus creating an active species for the group while the base catalyses the reaction by removing the proton from the alcohol, thus making it more reactive. This main difference between acid and base catalysts gives definitive variation to their catalytic activity.

\subsection{Enzyme Catalyst}

The enzyme catalyst has been discovered to be a potential catalyst for biodiesel production. The enzyme catalyst shows good thermal stability, good separation of products, is capable of being regenerated and reused and has good tolerance towards the high level of FFA in the feedstock. However, the main drawback was the cost of these biocatalysts, since they were found to be more expensive than most of the heterogeneous catalysts [19]. Most of the enzyme catalysts were prepared via immobilisation techniques, where the cell biocatalyst was immobilised within biomass support particles. This is the main advantage of this catalyst since the immobilisation can be achieved spontaneously during batch cultivation and no purification is needed [20]. Few studies have been carried out using biocatalysts in biodiesel production with lipase catalyst resulted a good yield of biodiesel in the transesterification process. An immobilised lipase has also been utilised in the methanolysis of corn oil under supercritical conditions, and this resulted in more than 98\% of FAME conversion. The utilisation of a lipase catalyst in continuous biodiesel production has also been investigated by with a three-step transesterification with methanol was conducted using a series of columns, packed with immobilised Candida lipase. Under the optimal condition, the final conversion ratio of FAME obtained was approximately 90-92\%. Another research on continuous systems using immobilized lipase from the Burkholderias cepacia (IM BS-30) catalyst was carried out [21]. Under the optimal conditions, approximately 96\% FAEE yield was achieved.

\section{Reaction Parameters Involved in Biodiesel Production}

The chemical reaction takes place when the oil is mixed with the alkoxide (alcohol-catalyst mix). This requires certain conditions of time, temperature and stirring. Since alcohols and oils do not mix at room temperature, the chemical reaction is usually carried out at a higher temperature and under continuous stirring, to increase the mass transfer between the phases. Usually, emulsions form during the course of the reaction; these are much easier and quicker to destabilize when methanol is used, in comparison to ethanol due to the greater stability of emulsions formed, difficulties arise in the phase separation and purification of biodiesel when ethanol is used in the reaction. The transesterification process may be carried out at different temperatures. For the same reaction time, the conversion is greater at higher temperatures. Since the boiling point of methanol is approximately $68^{\circ} \mathrm{C}(341 \mathrm{~K})$, the temperature for transesterification at atmospheric pressure is usually in the range between 50 and $60^{\circ} \mathrm{C}$. It is very useful to know the chemical composition of the mixture during the reaction; then, if the reaction mechanism and kinetics are known, the process can be optimized. However, the determination of the mixture composition is not easy, since more than a hundred substances are known to be present [11] for instance, for biodiesel production from rapeseed oil (whose main SFAs are palmitic, oleic, linoleic and linolenic) and methanol, with potassium hydroxide as a catalyst, it could be theoretically possible to find 64 isomers of triglycerides, 32 diglycerides, 8 monoglycerides, their methyl esters, potassium salts of the fatty acids, potassium methoxide, water, etc. The studies on this subject [12] indicate the following general guidelines:

- For longer reaction times, the concentration of triglycerides diminishes the concentration of esters, increases and the concentration of monoand diglycerides increases to a maximum and then decreases.

- Most of the chemical reaction takes place during the first minutes.

- The absence of mono- and diglycerides at the beginning of the chemical reaction and the increase and reduction of their concentration during the reaction confirm that the production of esters from the triglycerides takes place in three steps, as represented in the equations below:

$$
\begin{aligned}
& \mathrm{TG}+\mathrm{MOH} \underset{\mathrm{KOH}}{\stackrel{\mathrm{KOH}}{\longrightarrow}} \mathrm{DG}+\mathrm{ME} \\
& \mathrm{DG}+\mathrm{MOH}+\mathrm{ME} \\
& \mathrm{MG}+\mathrm{MOH} \stackrel{\mathrm{KOH}}{\longrightarrow} \mathrm{G}+\mathrm{ME}
\end{aligned}
$$

where MOH indicates methanol, ME are methyl esters, TG, DG and MG are tri-, di- and monoglycerides, respectively and $\mathrm{G}$ is glycerine.

Several methods, with different levels of equipment complexity and training requirements, have been devised to analyze samples that are mixtures of fatty acids and esters from mono-, di-, and triglycerides obtained from transesterification of vegetable oils. It must be noted that thin layer chromatography (TLC) provides essentially qualitative information about the sample composition, as distinct from the other methods, that can be used for quantitative analysis. However, the simplicity, speed and low cost of TLC make it quite attractive as a technique for process optimization and routine checks, especially in smalland medium-scale production plants, and also for training purposes.

\subsection{Reaction Time and Temperature}

The rate of reaction is significantly influenced by the reaction temperature and time [22]. If the transesterification reaction is given enough time, the reaction will proceed to near completion even at room temperature [23]. For the reactions operated in ambient pressure, the selection of temperature is usually dependent on the boiling point of the solvent used. If the chosen temperature is higher that the boiling point of the solvent, it will evaporate the alcohol and it results in lower ester conversion.

The range of temperature that is commonly used by researchers for biodiesel production is $318-353 \mathrm{~K}$ for ambient reaction processes and could go up to 473-573 K under pressurised systems. A higher temperature was also used when supercritical methanol (reaction temperature between $623 \sim 673 \mathrm{~K}$, pressure between $45 \sim 65 \mathrm{MPa}$ ) was employed for the biodiesel reaction. The effect of temperature on the transesterification process, and the findings showed that any temperatures higher than $323 \mathrm{~K}$ had a negative impact on the virgin oils but gained a positive feedback for waste oils with higher viscosities. However, this condition is applicable only when FFA removal pretreatment step is introduced during the early stage of the process. Higher temperature also favours the saponification process and must be avoided. The conversion rate of FAAE was usually high in the early stage of the transesterification reaction but slowly declined due to the lesser driving force. 


\subsection{Mixing Intensity and Mode of Stirring}

Mixing is one of the key factors in optimising the production of biodiesel, as oils and fats are partially miscible in a methanol solution. Once the reactants are totally mixed with each other, an increase in stirring speed is unnecessary. The studies on the effect of different speeds in the transesterification of Pongamia pinnata with methanol [24]. The reaction was conducted at three stirring speeds, which was at 180,360 and 600 revolution per minute (rpm). They identified that $180 \mathrm{rpm}$ did not cause any significant impact on the yield of FAME and led to an incomplete reaction. On the other hand, 360 and 600 rpm stirring speeds show the same yield, i.e. $97 \%$ FAME after $3 \mathrm{~h}$ of reaction. The mode of stirring also plays an important role in the conversion of FAAE. The magnetic stirrer was replaced with a mechanical stirrer at the same stirring speed, the yield of biodiesel increased from $85 \%$ to $89.5 \%$. This was probably due to the formation of a more complete solution using the rigorous mixing introduced by mechanical stirring. A low frequency of ultrasonic irradiation can also be used for transesterification. The transesterification of triolein using different types of stirring conditions i.e., mechanical stirring and ultrasonic agitation. Ultrasonic agitation was found to produce a higher conversion yield than the conventional mechanical stirring. In addition by using ultrasonic mixing, the reaction rate constants were three to five time higher than those reported in the literature for mechanical agitation. The ultrasonic-assisted transesterification only required an hour to achieved 95\% yield compared to $2-4 \mathrm{~h}$ with conventional stirring. Generally, by using ultrasonic agitation, a higher FAAE conversion was achieved in a shorter reaction time. However, research claimed that ultrasonic agitation is only workable when the reaction occurs under the most favourable conditions $(2 \% \mathrm{w} / \mathrm{w} \mathrm{NaOH}, 7: 1$ molar ratio of methanol to oil and $333 \mathrm{~K}$ ). Apart from that, the main obstacle is the price of the ultrasonic equipment, which is far more expensive compared to the conventional agitation method.

\subsection{Separation and Purification of Biodiesel of Production}

The separation process is one of the most crucial parts of biodiesel production. The product from the transesterification process is normally composed of FAAE, glycerine, alcohol, catalyst and unreacted glycerides. The properties of the fuel are strongly influence by the purity of the biodiesel product. Normally, the by-product glycerine is separated from FAAE using a simple gravitational settling method and left for a certain period of time. The separation process using the settling or centrifugal tank was considered to be cost effective. Biodiesel can also be separated by centrifugation and membrane purification. Centrifugation techniques offer a faster separation process compared to traditional settling techniques, however the high operating cost becomes a major concern. Membrane purification is the latest technology in biodiesel separation. It was found to produce a high quality of biodiesel, besides being energy efficient. However, problems such as the saponification reaction and an excess of alcohol could lead to difficulty during the separation process. The saponification reaction creates a stable emulsion between glycerine and biodiesel and this emulsion reduces the product yield. On the other hand, excess alcohol tends to act as a solubiliser and sometimes decelerates the separation process. Usually, alcohol is removed after the separation of glycerine and FAAE. Then, the FAAE is subjected to the purification process to remove impurities such as traces of glycerine, methanol, unreacted triglycerides and other by-products. Biodiesel purification methods can be classified into two categories: wet washing technologies and dry washing technologies.

\section{Current of Biodiesel Technologies}

Currently several alternatives are been employed to increase the conversion rates and the yields of esters in order to lower production costs and improve biodiesel product quality and presented as follows:

\subsection{Catalytic Conversion}

The problems associated with the homogeneous catalysts are the high consumption of energy and expensive separation of the homogeneous catalyst from the reaction mixture. Heterogeneous catalysts is another successful alternative is explored [25] to circumvent the difficulties with homogeneous catalysts for transesterification of high FFA-containing oils.

Heterogeneous catalyst developed to eliminate the need for aqueous quenching and elimination metal salts (soaps) [26] but the conversion for most of the heterogeneous are not high enough to be used for industrial based production [27] and relatively prolonged reaction period. There have also been experiments aimed at replacing the sodium and potassium compounds with basic ammonium compounds as catalysts or reactants such as amines, amino guanidines, nitro guanidine's and triamino (imino) https://doi.org/10.30799/jacs.181.18040105 phosphoranes. The guanidines are the more active catalysts, the activity following their relative basicity. At a concentration of $3 \%$ was similar to that of potassium carbonate at the same concentration. The saturated aqueous solution of guanidine carbonate has a $\mathrm{pH}$ of $11 \sim 11.5$. The aqueous solution of free guanidine, on the other hand, gives just as strong an alkaline reaction [28]. $\mathrm{KOH}$ loaded on $\mathrm{Al}_{2} \mathrm{O}_{3}$ and Na-zeolite supported as heterogeneous catalysts, though leaching of potassium species in both spent catalysts was observed, biodiesel yield of $91.07 \%$ was reported [29] at temperatures below $70{ }^{\circ} \mathrm{C}$ within $2-3 \mathrm{~h}$ at a $1: 15$ molar ratio of palm oil to $\mathrm{MeOH}$ and a catalyst amount of 3-6 wt\%.

\subsection{Supercritical Process}

Trigliceride (TG) utilization in the presence of an acid or alkali catalyst is affected by high level of water content and free fatty acid (FFA) with undesirable saponified products. Hence the study to reduce catalyst has attracted interest in water-added supercritical method with a feature of easier product separation. The glycerol (side reaction in biodiesel process) is more soluble in water than in $\mathrm{MeOH}[30,31]$. Single phase medium using supercritical fluid (SCF) due to the creation of a single phase environment has some unique advantages including increased species mixing, heat and mass transfer, fast reaction typically at a few minutes level. These systems are environmentally benign, and have good scalability, as well as being simple and easy for continuous production. The SCFs is ideal for separation and extraction of useful products and for oxidation of organic materials [32]. For most of the supercritical methods of biodiesel production, the reaction requires temperatures of $340-400{ }^{\circ} \mathrm{C}$ and pressures of 20-70 MPa. Rapeseed oil was treated at $250-350{ }^{\circ} \mathrm{C}, 43 \mathrm{MPa}$ with a molar ratio of 42 in $\mathrm{MeOH}$ for transesterification to biodiesel fuel. By this $\mathrm{MeOH}$ approach, crude vegetable oil as well as its wastes could be readily used for biodiesel fuel production in a simple preparation. Regardless of the content of water supercritical MeOH method does not require a catalyst and the FFA in the oils are esterified at once [33].

\subsection{Co-Solvent}

Enhancing solubility, addition of a co-solvent is to create a single phase greatly accelerated the reaction so that it reached substantial completion in a few minutes [34]. The technique is applicable for use with other alcohols and for acid-catalyzed pretreatment of high free fatty acid feed stocks. Comparison of various co-solvent dimethyl ether (DME), diethyl ether (DEE), tert-butyl methyl ether (TBME) and tetrahydrofuran (THF) [35] to synthesize biodiesel from sunflower oil by using a KOH catalyst at $25{ }^{\circ} \mathrm{C}$ in a closed batch reactor was reported [36] with addition of a cosolvent enhanced the transesterification rate at the $\mathrm{MeOH} /$ oil molar ratio of 6 at $25{ }^{\circ} \mathrm{C}$, and sunflower oil was almost completely converted into biodiesel after 20 min reaction while only approximately $78 \%$ conversion was reached in the absence of a co-solvent. The oil conversion was influenced by the cosolvent/ $\mathrm{MeOH}$ molar ratio, $\mathrm{MeOH} /$ oil molar ratio, and catalyst concentration. However, the homogeneous flow was broken with the formation of immiscible glycerol, and transformed to a dispersed flow of fine glycerol droplets. The problem of immiscibility of $\mathrm{MeOH}$ and vegetable oil leading to a mass-transfer resistance in the transesterification of vegetable oil [37] can be overcome by this method amongst many other techniques being developed like membrane separation and inert dopant [38].

\subsection{Microwave Method}

Microwave irradiation is a well-established methodology to improve extraction and accelerate chemical reactions such as those of hydrolysis and esterification [39]. Because of its convenience, rapidity, and economy advances in equipment design, trends in electrical energy costs, and research on food properties have provided a basis for modeling microwave heating patterns that should stimulate the development of new and improved commercial food processes [40].

In conventional heating of transesterification process (batch, continuous, and super critical $\mathrm{MeOH}$ process), heat energy is transferred to the raw material through convection, conduction, and radiation from surfaces of the raw material as shown when triglyceride (TG) in soaked soybeans were already hydrolyzed into diglyceride (DG) and free fatty acids during soaking and were further hydrolyzed by microwaves. Satisfactory transesterification was achieved in a short time (30s), with alcohol to oil molar ratio $12: 1$ and the continuous conversion of waste frying palm oil to ethyl ester was over $97 \%$. Although, the mechanism of the microwave effect on a chemical reaction, whether thermal or nonthermal, is debatable [41]. The transesterification results clearly establish that there is considerable enhancement in reaction rates. This brings about considerable time saving as well as cost with $100 \%$ biodiesel yield by applying microwave irradiation for two minutes compared to one hour with the conventional technique, with adjusted temperature to $65^{\circ} \mathrm{C}$, a 
$\mathrm{MeOH} /$ oil molar ratio of $6: 1$ and potassium hydroxide (1\%) used as a catalyst has been studied $[42,43]$ and showed that microwave-enhanced biodiesel is not, at least, inferior to that produced by the conventional technique.

\subsection{Ultrasonic Reactor Method}

An ultrasonic field is known to produce unique chemical and physical effects that arise from the collapse of the cavitation bubbles [44]. Their uses have been cited in synthesis of nanostructured materials, processing of biomass, sonofusion, sonodynamic therapy, and sonochemical degradation of pollutants [45] and hazardous chemicals [46]. A low frequency ultrasonic irradiation can be used to produce emulsions from immiscibility liquids and help generate small droplets and large interfacial areas if the ultrasonication device is placed near the liquid-liquid interface in a two phase reaction system $[47,48]$.

The differences in a heterogeneous catalytic reaction for cavitating and non-cavitating ultrasound incorporating an inert dopant, which does not partake in solution chemistry to enable facile transition from high power non-cavitating to cavitating condition as not all liquid readily cavitation. The mechanism for discriminating between physical and chemical effects of ultrasound with different conditions have been coupled to a bubble dynamics mode [49] and the result is attributed to the difference in intensity of microturbulence produced by cavitation bubbles in oil and $\mathrm{MeOH}$. This effect is a low intensity of microturbulence generated by cavitation bubbles in oil, which restrict an intimate dispersion of oil in $\mathrm{MeOH}$ for high alcohol to oil molar ratios.

The optimum alcohol to oil molar ratio for the experimental system used in this study is 12:1. Transesterification of TG with various alcohols has been shown [50] under the low frequency ultrasonic irradiation (24 $\mathrm{KHz})$, stirring conditions $(600 \mathrm{rpm})$. The optimal reaction condition was obtained with an alcohol to TG ratio of 6:1, low frequency ultrasonication $(24 \mathrm{KHz})$ and mechanical stirring $(600 \mathrm{rpm})$ with $\mathrm{MeOH}$ gave high yields of methyl esters $(95 \%)$ after a short reaction time $(20 \mathrm{~min})$ similar to those using mechanical stirring. Use of ultrasonication in conventional transesterification with ethanol gave similar yields to those using mechanical stirring but significantly lower than respective yields using $\mathrm{MeOH}$ [51].

\subsection{Oscillatory Flow Reactor for Transesterification Reaction}

Oscillatory flow reactor (OFR) is used to produce biodiesel through some improvement in mixing intensity between reactants. OFR is a novel type of continues flow reactor, containing tubes with equally spaced orifice plate baffles. An oscillatory motion is superimposed upon the net flow of the process fluid, creating flow patterns conducive for efficient heat and mass transfer, whilst maintaining plug flow regime [52]. In addition, each baffle essentially behaves as a stirred tank that lead to excellent mixing and suspension by creating vortices between orifice baffles and oscillating fluid [53]. Designing a biodiesel reactor especially when heterogeneous catalysts are used due to the presence of three immiscible phases (oil-alcohol-catalyst) at the initial stage of reaction. Thus, improvement in mixing and suspension of catalysts tend to produce higher yield of biodiesel in a shorter reaction time compared to conventional batch-type stirred tank reactor.

Apart from that, OFR allows longer residence time as the mixing is independent of the net flow and hence the reactor length-to-diameter ratio can be reduced. This is an important plus point if the process is scaled up for commercial application in order to reduce the overall capital and pumping cost. The reaction was performed at temperature of $20-70{ }^{\circ} \mathrm{C}$, residence time of 10-30 $\mathrm{min}$ and molar ratio of methanol to oil was maintained at 1.5 . Pure sodium hydroxide $(32.4 \mathrm{~g})$ was dissolved in pure methanol initially at $40{ }^{\circ} \mathrm{C}$ for $1 \mathrm{~h}$. It was found that at $50{ }^{\circ} \mathrm{C}$ and $30 \mathrm{~min}$ of reaction time, nearly $99 \%$ of biodiesel was produced. Moreover, the product contains negligible amount of triglyceride and diglyceride.

\subsection{Mechanical Stirring Method}

Several commercial processes for FAME production have been developed. In conventional (mechanical stirring method) industrial biodiesel processes, vegetable oil methanolysis is achieved using a homogeneous catalyst system operated in either batch or continuous mode. Sodium hydroxide or sodium methylate is often used as catalyst. Sodium is recovered after the transesterification reaction as sodium glycerate, sodium methylate, and sodium soaps in the glycerol phase. In the mechanical stirring reaction, the temperature is $60-70^{\circ} \mathrm{C}$, and it takes about an hour and half for the reaction to proceed to completion. The alcohol and the alkali metal hydroxide catalyst are first mixed before the reaction in a separate unit to form the metal alkoxide. The alcohol and the alkoxide catalyst are then mixed with oil in the reactor. The reactor is a batch reactor with stirrer, or a continuous or semi-continuous stirred tank reactor. A condenser is used to condense the alcohol continuously. The boiling point of the alcohol is in the range of the reaction temperature. Oil and alcohol are immiscible; they are constantly stirred, and the reaction takes place at the interface of two phases. The reaction is described by second order reaction kinetics. The stoichiometric ratio of triglyceride and alcohol for the reaction is $3: 1$, but $6: 1$ molar ratio is the optimal molar ratio used to push equilibrium to one side for maximum biodiesel conversion (97 98\%).

\section{Conclusion}

The dwindling reserve of conventional energy resources and their associated environmental problems have increased the awareness to seek for alternative renewable and sustainable resources for fuel production. The production of biofuel is now escalating as a replacement of fossil fuel. Biodiesel has become beguiling nowadays for its environmental benefits and it seems an alternative fuels for future. It is made from renewable biological sources such as vegetable oils and animal fats. It is biodegradable and nontoxic, has low emission profiles and also environmentally beneficial. The best method for preparing higher amount of Biodiesel from vegetable oils which are waste and discarded. The results showed higher levels of Biodiesel formation from acid catalysis and enzymatic usage. But it was seen that in all the cases heat is required for the transesterification to occur in larger scale and the quality of the Biodiesel formed is also comparable to the pure diesel.

\section{Acknowledgements}

This research work was supported by University Grants Commission, New Delhi, India (No. 540/27/DRS/2007, SAP-1) and UGC-RGNF, India (No. F.1/2012-13/RGNF-2012-13-SC-WES-17229). One of the author Prof. M.N. Roy, is grateful to the UGC, New Delhi, Govt. of India, for being awarded a one-time grant under the Basic Scientific Research via the Grant-in-Aid no. F4-10/2010 (BSR) regarding his active service for augmenting of research facilities to aid further research work.

\section{References}

[1] A.E. Atabani, A.S. Silitonga, I.A. Badruddin, T.M.I. Mahlia, H.H. Masjuki, S. Mekhilef, A comprehensive review on biodiesel as an alternative energy resource and its characteristics, Renew. Sustain. Energy Rev. 16(4) (2012) 2070-2093.

[2] A.L. Ahmad, N.H.M. Yasin, C.J.C. Derek, J.K. Lim, Microalgae as a sustainable energy source for biodiesel production: A review, Renew. Sustain. Energy Rev. 15(1) (2011) 584-593.

[3] I.M. Atadashi, M.K. Aroua, A.R. Abdul Aziz, M.N. Sulaiman, Refining technologies for the purification of crude biodiesel, Appl. Energy 88 (2011) 4239-4251.

[4] M. Berrios, R.L. Skelton, Comparison of purification methods for biodiesel, Chem. Eng. Jour. 144 (2008) 459-465.

[5] M. Canakci, The potential of restaurant waste lipids as biodiesel feedstocks, Bioresour. Technol. 98 (2007) 183-190.

[6] M.C.G. Albuquerque, I. Jiménez-Urbistondo, J. Santamaría-González, J.M. Mérida-Robles, R. Moreno-Tost, E. Rodríguez-Castellón, et al., CaO supported on mesoporous silicas as basic catalysts for transesterification reactions, Appl. Catal. A: Gen. 334 (2008) 35-43.

[7] M.I. Al-Widyan, A.O. Al-Shyoukh, Experimental evaluation of the transesterification of waste palm oil into biodiesel, Bioresour. Technol. 85 (2002) 253-256

[8] M. Berrios, M.A. Martin, A.F. Chica, A. Martin, Study of esterification and transesterification in biodiesel production from used frying oils in a closed system, Chem. Eng. Jour. 160 (2010) 473-479.

[9] J.A. Lercher, C. GriJndling, G. Eder-Mirth, Infrared studies of the surface acidity of oxides and zeolites using adsorbed probe molecules, Catal. Today 27 (1996) 353-376.

[10] S.C.M. Dos Reis, E.R. Lachter, R.S.V. Nascimento, J.A. Rodrigues, M.G. Reid, Transesterification of brazilian vegetable oils with methanol over ion exchange resins, J. Am. Oil Chem. Soc. 82 (2005) 661-665.

[11] C.L. Bianchi, D.C. Boffito, C. Pirola, V. Ragaini, Low temperature de-acidification process of animal fat as a pre-step to biodiesel production, Catal. Lett. 134 (2010) 179-183.

[12] M. Di Serio, R. Tesser, L. Pengmei, E. Santacesaria, Heterogeneous catalysts for biodiesel production, Energy Fuels 22 (2008) 207-217.

[13] J. Barrault, S. Bancquart, Y. Pouilloux, Selective glycerol transesterification over mesoporous basic catalysts, Comptes. Rendus Chimie 7 (2004) 593-599.

[14] H-X. Bai, X-Z. Shen, X-H. Liu, S-Y. Liu, Synthesis of porous CaO microsphere and its application in catalyzing transesterification reaction for biodiesel, Trans. Nonfer. Metal. Soc. China 19 (2009) 674-677.

[15] W. Chu, X. Yang, X. Ye, Y. Wu, Vapor phase esterification catalyzed by immobilized dodecatungstosilicic acid (SiW12) on activated carbon, Appl. Catal. A Gen. 145 (1996) 126-140. 
[16] A.C. Carmo, L.K.C. De Souza, C.E.F. Da Costa, E. Longo, J.R. Zamian, G.N. Da Rocha Filho, Production of biodiesel by esterification of palmitic acid over mesoporous aluminosilicate Al-MCM-41, Fuel 88 (2009) 461-468.

[17] A.K. Endalew, Y. Kiros, R. Zanzi, Inorganic heterogeneous catalysts for biodieselproduction from vegetable oils, Biomass Bioener. 35 (2011) 37873890

[18] N. Ellis, F. Guan, T. Chen, C. Poon, Monitoring biodiesel production (transesterification) using in situ viscometer, Chem. Eng. Jour. 138 (2008) 200206.

[19] N.S. Talha, S.S. Silitonga, Overview of catalysts in biodiesel production, Arpn. J. Eng. Appl. Sci. 11(1) (2016) 439-448.

[20] H. Fukuda, A. Kondo, H. Noda, Biodiesel fuel production by transesterification of oils, J. Biosci. Bioeng. 92(5) (2001) 405-416.

[21] T.A. Foglia, L.A. Nelson, W.N. Marmer, Production of biodiesel, lubricants and fuel and lubricant additives, US Patent 5,713, 1965

[22] B. Freedman, E.H. Pryde, W.H. Kwolek, Thin layer chromatography/flame ionization analysis of transesterified vegetable oils, J. Am. Oil Chem. Soc. 61(7) (1984) 1215-1220.

[23] M.W. Formo, Ester reactions of fatty materials, J. Am. Oil Chem. Soc. 31 (1954) 548-553.

[24] L.C. Meher, D. Vidya Sagar, S.N. Naik, Technical aspects of biodiesel production by transesterificatiom: a review, Renew. Sustain. Energy Rev. 10(3) (2006) 121.

[25] F. Ma, M.A. Hanna, Biodiesel production: A review, Bioresour. Technol. 70(1) (1999) 1-15.

[26] W. Zhou, D.G.B. Boocock, Phase behavior of the base-catalyzed transesterification of soybean oil, J. Am. Oil Chem. Soc. 83(12) (2006) 10411045.

[27] W. Xie, H. Peng, L. Chen, Calcined Mg - Al hydrotalcites as solid base catalysts for methanolysis of soybean oil, J. Mol. Catal. A Chem. 246 (2006) 24-32.

[28] U. Schuchardt, R. Sercheli, R.M. Vargas, Transesterification of vegetable oils: A review, J. Braz. Chem. Soc. 9 (1998) 199-210.

[29] K. Noiroj, P. Intarapong, A. Luengnaruemitchai, S. Jai-In, A comparative study of $\mathrm{KOH} / \mathrm{Al}_{2} \mathrm{O}_{3}$ and $\mathrm{KOH} / \mathrm{NaY}$ catalysts for biodiesel production via transesterification from palm oil, Renew. Ener. 34 (2009) 1145-1150.

[30] D. Kusdiana, S. Saka, Effects of water on biodiesel fuel production by supercritical methanol treatment, Bioresour. Technol. 91 (2004) 289-295.

[31] K.G. Georgogiannia, M.G. Kontominasa, P.J. Pomonisa, D. Avlonitisb, V. Gergisc, Conventional and in situ transesterification of sunflower seed oil for the production of biodiesel, Fuel Proc. Technol. 89(5) (2008) 503-509.

[32] D. Wen, H. Jiang, K. Zhang, Review: Supercritical fluids technology for clean biofuel production, Prog. Natur. Sci. 19(3) (2009) 273-284.

[33] D. Kusdiana, S. Saka, Effects of water on biodiesel fuel production by supercritical methanol treatment, Bioresour. Technol. 91 (2004) 289-295.

[34] D. Royon, M. Daz, G. Ellenrieder, S. Locatelli, Enzymatic production of biodiesel from cotton seed oil using t-butanol as a solvent, Bioresour. Technol. 98 (2007) 648-653.
[35] G. Guan, N. Sakurai, K. Kusakabe, Synthesis of biodiesel from sunflower oil at room temperature in the presence of various co-solvents, Chem. Eng. Jour. 146 (2009) 302-306.

[36] D. Wen, H. Jiang, K. Zhang, Review: Supercritical fluids technology for clean biofuel production, Prog. Natur. Sci. 19(3) (2009) 273-284.

[37] D. Kusdiana, S. Saka, Effects of water on biodiesel fuel production by supercritical methanol treatment, Bioresour. Technol. 91 (2004) 289-295.

[38] L. Saikia, J.K. Satyarthi, D. Srinivas, P. Ratnasamy, Activation and reactivity of epoxides on solid acid catalysts, J. Catal. 252 (2007) 148-160.

[39] R. Ipsita, M.N. Gupta, Applications of microwaves in biological sciences, Curr. Sci. 85(12) (2003) 1685-1693.

[40] C.P. Tan, Y.B. Che Man, S. Jinap, M.S.A. Yusoff, Effects of microwave heating on changes in chemical and thermal properties of vegetable oils, J. Am. Oil Chem. Soc. 78 (2001) 1227-1232.

[41] N. Saifuddin, K.H. Chua, Production of ethyl ester (biodiesel) from used frying oil: optimization of transesterification process using microwave irradiation, Malays. J. Chem. 6(1) (2004) 77-82.

[42] A.A. Refaat, S.T. El Sheltawy, Comparing three options for biodiesel production from waste vegetable oil, WIT Trans. Ecol. Environ. 84 (2015) 47-54.

[43] H. Yoshida, S. Takagi, Microwave roasting and positional distribution of fatty acids of phospholipids in soybeans (Glycine max L.), J. Am. Oil Chem. Soc. 74 (1997) 915-920.

[44] C. Bondy, K. Sollner, Mechanism of emulsification by ultrasonic waves, J. Trans. Faraday Soc. 31 (1935) 835-843.

[45] H.D. Hanh, N.T. Dong, K. Okitsu, Y. Maeda, R. Nishimura, Effects of molar ratio, catalyst concentration and temperature on transesterification of triolein with ethanol under ultrasonic irradiation, J. Japan Petrol. Inst. 50 (2007) 195-199.

[46] U. Schuchardt, R. Sercheli, R.M. Vargas, Transesterification of vegetable oils: A review, J. Braz. Chem. Soc. 9 (1998) 199-210.

[47] M. Sivakumar, P. Senthilkumar, S. Majumdar, A.B. Pandit, Ultrasound mediated alkaline hydrolysis of methyl benzoate-reinvestigation with crucial parameters, Ultrasonic Sonochem. 9(1) (2002) 25-30.

[48] J.K. Satyarthi, D. Srinivas , P. Ratnasamy, Influence of surface hydrophobicity on esterification of fatty acids over solid catalysts, Energy Fuel 24 (2010) 21542161.

[49] A. Kalva, T. Sivasankar, S.V. Moholkar, Physical mechanism of ultrasoundassisted synthesis of biodiesel, Indust. Eng. Chem. Res. 48(1) (2009) 534-544.

[50] P.T. Vasudevan, M. Briggs, Biodiesel production - current state of the art and challenges, J. Indust. Microbiol. Biotechnol. 35 (2008) 421-430.

[51] P.R. Gogate, R.K. Tayal, A.B. Pandit, Cavitation: A technology on the horizon, Curr. Sci. 91 (2006) 35-46.

[52] A.P. Harvey, M.R. Mackley, T. Seliger, Process intensification of biodiesel production using a continuous oscillatory flow reactor, J. Chem. Technol. Biotechnol. 78 (2003) 338-341.

[53] M. Zheng, R.L. Skelton, M.R. Mackley, Biodiesel reaction screening using oscillatory flow meso reactors, Proc. Safety Environ. Protect. 85 (2007) 365371. 